\title{
The Relationship Between Saccharin and Alcohol Intake in Rats
}

\author{
BLAKE A. GOSNELL ${ }^{1}$ AND DEAN D. KRAHN \\ University of Michigan Medical Center, Department of Psychiatry, Ann Arbor, MI 48109-0656
}

Received 13 September 1991; Accepted 6 December 1991

\begin{abstract}
GOSNELL, B. A. AND D. D. KRAHN. The relationship between saccharin and alcohol intake in rats. ALCOHOL 9(3) 203-206, 1991. - Male rats were given daily sessions during which a palatable saccharin solution was available. Based on intakes averaged over 3 days, groups with low, intermediate, or high intake of saccharin were formed. These rats were then given daily sessions in which alcohol $(2-8 \%)$ or water were available. Initially, sessions were conducted with rats on a food restriction schedule; in later sessions, food was available ad lib. When rats were food restricted, there were no differences among the groups in terms of alcohol or water intake. When the food restriction schedule was discontinued, alcohol intake in the intermediate and high saccharin intake groups was generally higher than that of the low saccharin group. On the final series of alcohol sessions, the high saccharin group consumed significantly more $2 \%$ and $6 \%$ alcohol than the low saccharin group. These results are consistent with reports which have found that rats selected for high or low alcohol intake have corresponding high and low intakes of saccharin.
\end{abstract}

Alcohol Saccharin Taste preference Oral drug intake

LARGE individual differences in the degree to which alcohol is self-administered have been observed in rats. In fact, these differences in self-administration have led to the development of genetic strains of rats that differ dramatically in alcohol preference $(19,26)$. However, it is unclear whether differences in alcohol preference are specific for alcohol or are paralleled by differences in the self-administration of other substances. Forsander (8) has reported that rats of the alcohol-preferring AA strain consumed more fat than those of the alcohol nonpreferring ANA strain. Furthermore, we have recently reported that rats selected on the basis of their preference for dietary fat differed in the amount of alcohol they would consume (16). Specifically, rats that self-selected a diet high in fat consumed more alcohol than rats self-selecting a diet high in carbohydrate. Marks-Kaufman and Lipeles (20) found that those rats which went on to become oral consumers of morphine consumed more dietary fat than those that would not drink the morphine solution. Thus, there may be a general, positive relationship between the preference for dietary fat and the self-administration of drugs.

Sweet taste is another quality of food which is reinforcing and/or preferred, and therefore, might interact or covary with the preference for (or self-administration of) alcohol and other drugs. Rats will ingest sweet solutions in the absence of deprivation $(7,22)$. In preference tests, they typically prefer the sweeter of two solutions $(10,33)$. In the "two bottle" paradigm for measuring alcohol preference, provision of saccha- rin, sucrose, or fat solutions as a "third choice" resulted in a decrease in alcohol consumption (18). Likewise, the availability of a saccharin/glucose solution decreased the self-administration of cocaine in rats (3), while the deprivation of a saccharin/glucose solution increased the self-administration of etonitazene (2) and cocaine (3). In rats selected for low and high alcohol self-administration, corresponding low and high intakes of saccharin solution have been noted $(13,25)$. To determine whether this relationship is reciprocal, we selected rats with high, intermediate, or low voluntary intakes of saccharin solution, and measured their subsequent intakes of alcohol solutions. We hypothesized that those rats which showed the greatest intake of saccharin would also show the greatest intake of alcohol.

\section{METHOD}

\section{Saccharin Intake and Group Formation}

Male Wistar rats (Sprague-Dawley Inc., Indianapolis, IN) $(n=52)$ were housed individually in stainless-steel cages in a room in which the lights were on from 7 a.m. to 7 p.m. Upon arrival into the lab, they were given ad lib access to water and standard lab chow. Six days later, water was removed from all cages. The next day, approximately 2 hours after the onset of the light cycle, they were moved to individual test cages and allowed to drink a $0.1 \%$ sodium saccharin solution (wt/

\footnotetext{
${ }^{1}$ Requests for reprints should be addressed to Blake A. Gosnell, University of Michigan Medical Center, Department of Psychiatry, MSRB-1, A520A, Box 0656, Ann Arbor, MI 48109-0656.
} 
vol) for $1 \mathrm{~h}$. The solution was presented in $25-\mathrm{ml}$ graduated burets fitted with stainless-steel sipper tubes. After this session, rats were returned to their home cages, where food was available ad lib; water deprivation was continued. This test procedure was repeated on the following day, except that water was returned following the saccharin-drinking session. Water was available ad lib for the remainder of the experiment. Daily 1-h saccharin drinking sessions were continued for an additional 13 days. In these sessions, both water and saccharin were available for $1 \mathrm{~h}$. Positions of the burets containing these fluids were reversed daily. On the basis of saccharin intakes averaged over the final three sessions, groups of low, intermediate, and high saccharin drinkers were formed $(n=8$ per group). These groups were then tested for alcohol intake and diet preferences as described below. Mean body weights, as measured on the day before the beginning of saccharin intake measures, were $311 \pm 3,312 \pm 2$, and $302 \pm 6 \mathrm{~g}$ for the low, intermediate, and high saccharin intake groups, respectively.

\section{Alcohol Intake}

The method of inducing alcohol intake was modified from that of Stewart and Grupp (27). On the day after groups were formed, all rats were deprived of food overnight. The next day, they were placed in the drinking test cages where food and water were available. Though not water deprived, rats consume water in association with eating. After 1 hour, the rats were returned to their home cages, where food was available for an additional $\mathbf{4}$ hours. Water was available at all times in the home cages. This procedure was repeated daily for the next 4 days. The water available in the test cage was then replaced with $2 \%$ ethanol (vol/vol) for the next 7 days. The ethanol concentration was then increased in $2 \%$ increments up to a concentration of $8 \%$, with seven sessions being conducted at each concentration. As with the first day, food was available to the rats for only 5 hours/day: 1 hour in the test cages and 4 hours in the home cages. After the final session with $8 \%$ ethanol, this restricted schedule ended, and food was available ad lib in the home cages. Daily 1-hour drinking sessions continued as described above, except that food was no longer available in the test cage. Seven daily sessions were conducted with $8 \%$ ethanol as the test solution. The ethanol concentration was then decreased to $0 \%$ (water) in $2 \%$ increments, with three daily sessions at each concentration. After the three water sessions, the concentration was then increased in $2 \%$ increments to $8 \%$, with three daily sessions at each concentration except $8 \%$, which was tested for 5 days. At each concentration, intake was averaged over the final three sessions if seven or more consecutive sessions were run at that concentration; when less than seven sessions were run, all except the first session were averaged.

\section{Saccharin Intake Retest}

To determine whether relative saccharin intakes remained stable after the alcohol intake sessions, the three groups were given seven daily sessions with $0.1 \%$ saccharin as the test fluid. The first session was three days after the final $8 \%$ ethanol session. In the initial saccharin sessions described above, water intake was negligible in all three groups. To simplify the retest procedures, therefore, water was not available simultaneously with the saccharin. Intakes on the final three sessions were averaged to yield saccharin retest scores.

\section{Data Analysis}

Intakes of the diets and the saccharin and alcohol solutions were compared across groups with Bonferroni $t$ tests (onetailed).

RESULTS

\section{Initial Saccharin Intake}

The low, intermediate, and high saccharin drinking groups consumed an average of $0.9 \pm 0.1,3.5 \pm 0.1$, and $8.8 \pm 1.6$ $\mathrm{ml}$, respectively. The mean intake of water, which was available along with saccharin, was low in all three groups (less than $0.3 \mathrm{ml}$ on all test days).

\section{Alcohol Intake}

During the food-restriction phase, mean intake of water $(0 \%)$ and the various alcohol solutions ranged from 7.0-12.0 $\mathrm{ml}$, with highest intakes occurring with $2 \%$ and $4 \%$ concentrations (Fig. 1, upper panel). Planned comparisons indicated no differences in intake among the low, middle, and high saccharin drinking groups at any alcohol concentrations. Once the food restriction schedule ended, intake during the daily drinking sessions decreased as expected (Fig. 1, lower panel). The alcohol concentration was gradually decreased to $0 \%$ (water) and then increased up to $8 \%$. All groups appeared to consume more in the ascending series than in the descending series. At each concentration, except the initial $8 \%$ test, mean intake of the middle and high saccharin drinking groups was greater than that of the low saccharin group. Planned comparisons indicated that in the second nondeprived sessions with $2 \%$ and $6 \%$ alcohol, mean intake of the high saccharin group was significantly greater than that of the low saccharin group (Bonferroni $t$ tests, one-tailed, $p<0.05$ ). The intake of water $(0 \%)$ by all groups was lower than the intake of all alcohol solutions. Mean intakes of water differed by less than $1.0 \mathrm{ml}$.

\section{Saccharin Intake Retest}

When saccharin intake was measured after alcohol testing, mean intakes for the low, middle, and high saccharin groups were $5.8 \pm 0.5,8.5 \pm 1.0$, and $13.3 \pm 2.1 \mathrm{ml}$, respectively. Repeated measure $t$-tests (two-tailed) indicated that all groups consumed significantly more saccharin in the retest than in the initial test $t_{7}=8.60,4.91$, and 4.97 , respectively, for the low, middle, and high saccharin groups, all $p$ values < 0.01 ). Thus, although mean intakes were increased by $4.5-5.0$ $\mathrm{ml}$, the relative positions of the means remained the same as at the beginning of the experiment. In addition, the two measures of saccharin intake were significantly correlated (Pearson $r=0.88$, Spearman $r=0.64, p<0.01$ ).

\section{Body Weight}

Body weights were measured several times during the course of the experiment. There were no significant differences among groups at any measurement. On the day after the completion of the saccharin retest measures, mean body weights were $509 \pm 13,499 \pm 10$, and $503 \pm 13 \mathrm{~g}$ for the low, intermediate, and high saccharin groups, respectively.

\section{DISCUSSION}

Rats selected for high levels of voluntary intake of saccharin solution showed a tendency to consume more alcohol than 

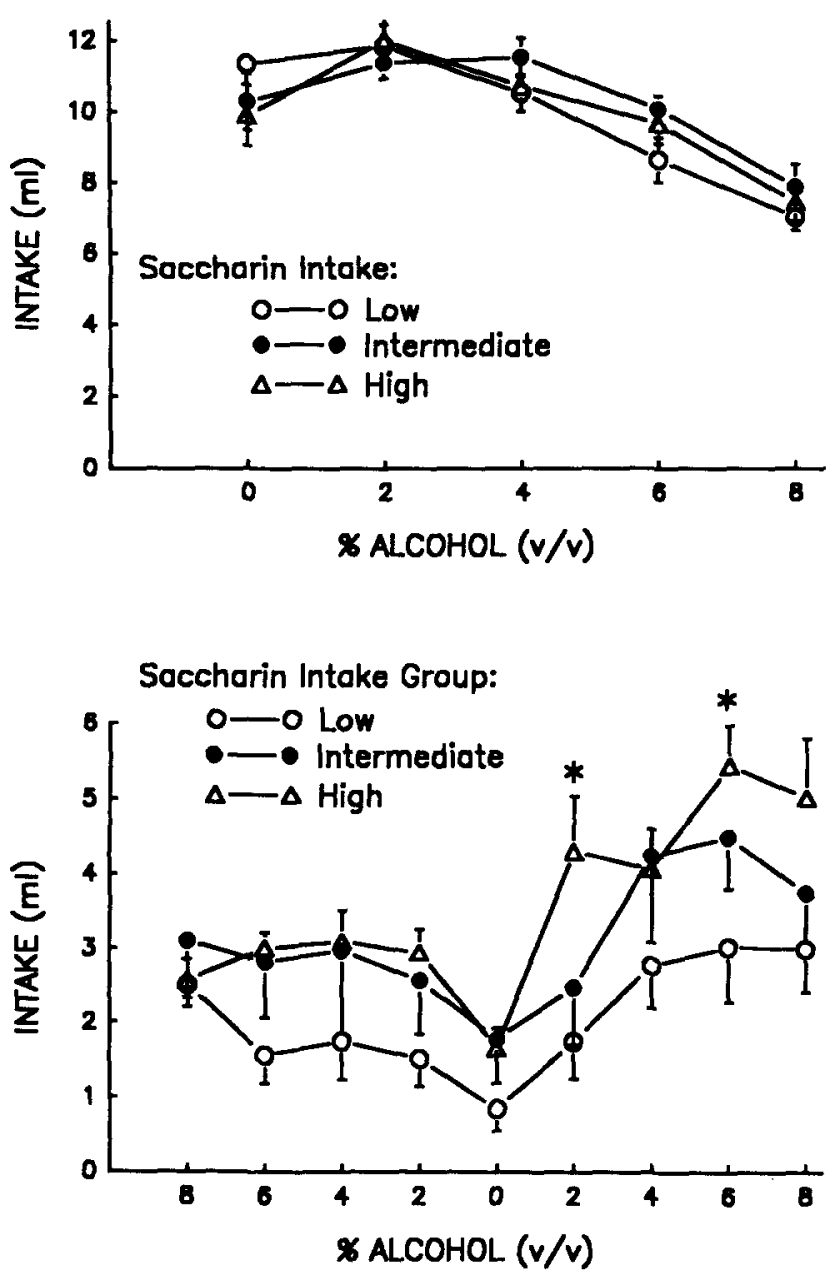

FIG. 1. (Top) Intake of alcohol by low, intermediate, and high saccharin consuming rats (means $\pm \mathrm{SEM}, n=8$ per group). Each point represents the average of the final three sessions at the indicated concentrations. Rats were on a food-restricted schedule, and the test session coincided with the first hour of food availability each day. (Bottom) Intake of alcohol by the same groups when food was available ad lib, except during the test session. Each point represents the average of 2-4 sessions. Asterisks indicate significant differences from the low saccharin intake group $(p<0.05$, one-tailed Bonferroni $t$ test).

rats selected for low levels of saccharin intake. This observed relationship is consistent with that reported by KampovPolevoy et al. (13). These authors measured intakes of quinine, saccharin, and alcohol solutions in rats. When groups were formed on the basis of initial consumption of alcohol, they noted a positive relationship between alcohol consumption and consumption of saccharin and quinine solutions in prior tests.

One possible explanation for the tendency of saccharinpreferring rats to consume more alcohol is that the rewarding effects of alcohol and saccharin consumption are mediated by the same brain mechanism. Wise (31) has contended that a common mechanism may mediate reward derived from drugs, electrical stimulation of the brain, and natural reinforcers such as food and water. With this view, one might predict that rats showing high and low rates of self-administration of one substance would also show corresponding high and low self-administration of other substances which activate the same reward system. A number of studies support the existence of such a relationship. Nichols and Hsiao (24) found that rats selectively bred for high and low susceptibility to opiate addiction (as measured by oral morphine consumption) also displayed corresponding high and low susceptibility to alcohol addiction. Similarly, rats selectively bred for high rates of brain electrical self-stimulation consume more saccharin solution than those bred for low rates of self-stimulation (9). Marks-Kaufman and Lipeles (20) noted that rats which would consume a morphine solution had a higher baseline preference for dietary fat than those rats that would not consume morphine. Finally, we recently found that rats with a high baseline preference for fat consumed more alcohol than those with a low fat preference (16).

A second possible explanation for the relationship between the intakes of saccharin and alcohol is that the two solutions are similar in taste. On the basis of taste reactivity and taste aversion generalization studies, several reports have concluded that the taste of alcohol has a sweet and a bitter component $(4,14,15)$. With our procedures, which allowed $1 \mathrm{~h}$ of access to alcohol per day, rats may not have consumed enough alcohol to permit learning about postingestive effects. Therefore, we cannot rule out the possibility that our observed differences in alcohol intake are due to taste factors alone. However, our results are consistent with those of Sinclair et al. (25), who used continuous access procedures to compare saccharin intake in alcohol-preferring and alcohol-avoiding lines of rats. They reviewed the issue of alcohol taste in detail, and concluded that their observed strain-related differences in saccharin preference are related more to differences in the postingestive effects of alcohol than to differences in alcohol taste reactivity.

It is important to note that when saccharin intake was retested after the alcohol sessions, the ordering of the group means (low, intermediate, and high intake) did not change. Intake in all three groups increased by approximately the same amount $(4.5-5 \mathrm{ml})$. This increase may reflect increased familiarity with the testing procedures. That the differences between the groups were observed on retest suggests that the groups actually differed in their acceptance of saccharin, rather than in their neophobic reactions to a novel taste or in their rates of adaptation to the testing procedures.

The interaction between the intake of sweet substances and the preference for and intake of drugs does not appear to be limited to laboratory animals, although laboratory studies in humans are lacking and should be performed. In a survey of eating and drinking habits among adolescents, increased alcohol intake was associated with increased intake of sugars, sweets, fats, and oils and with decreased intakes of complex carbohydrates (32). Recovering alcoholics who have the longest periods of postdetoxification sobriety report increased intake of sugar in beverages and increased carbohydrate intake (34). Sweet cravings are frequently reported by opiate addicts, and large intakes of sweet foods have been reported in this population $(23,28,30)$. Anorexic and bulimic patients have increased preferences for sweet tastants $(5,6)$ (although they typically deprive themselves of these foods) and increased rates of alcoholism and other substance abuse $(11,12$, $17,21,29)$. While clinical recommendations cannot be made on the basis of these findings in rats, it is of interest that 
literature published by Alcoholics Anonymous, and used in some treatment programs, indicates that "thousands of us - even many who said they had never liked sweets - have found that eating or drinking something sweet allays the urge to drink" (1). Thus, an understanding of the interactions between preference for sweet substances and the prefernence for and intake of drugs may be important in treatment and prevention in both drug-abusing and eating-disordered populations.

\section{ACKNOWLEDGEMENTS}

This research was supported by NIDA Grants DA05471 and DA06827. We thank David Averbach and Chetan Patel for technical assistance.

\section{REFERENCES}

1. Alcoholics Anonymous. Living sober. New York: Alcoholics Anonymous World Services, Inc.; 1987:23.

2. Carroll, M. E.; Boe, I. N. Increased intravenous drug selfadministration during deprivation of other reinforcers. Pharmacol. Biochem. Behav. 17:583-567; 1982.

3. Carroll, M. E.; Lac, S. T.; Nygaard, S. L. A concurrently available nondrug reinforcer prevents the acquisition or decreases the maintenance of cocaine-reinforced behavior. Psychopharmacol. 97:23-29; 1989.

4. DiLorenzo, P. M.; Kiefer, S. W.; Rice, A. G.; Garcia, J. Neural and behavioral responsivity to ethyl alcohol as a tastant. Alcohol $3: 55-61 ; 1986$

5. Drewnowski, A.; Bellisle, F.; Aimez, P.; Remy, B. Taste and bulimia. Physiol. Behav. 41:621-626; 1987.

6. Drewnowski, A.; Halmi, K. A.; Pierce, B. Taste and eating disorders. Am. J. Clin. Nutr, 46:442-450; 1987.

7. Ernits, T.; Corbit, J. D. Taste as a dipsogenic stimulus. J. Comp. Physiol. Psychol. 83:27-31; 1973.

8. Forsander, $\mathrm{O}$. A. The interaction between voluntary alcohol consumption and dietary choice. Alcohol Alcohol. 23:143-149; 1988.

9. Ganchrow, J. R.; Lieblich, I.; Cohen, E. Consummatory responses to taste stimuli in rats selected for high and low rates of self-stimulation. Physiol. Behav. 27:971-976; 1981.

10. Hursh, S. R.; Beck, R. C. Bitter and sweet saccharin preferences as a function of food deprivation. Psychol. Rep. 29:419-422; 1971.

11. Jonas, J. M.; Gold, M. S.; Sweeny, D.; Pottash, A. L. C. Eating disorders and cocaine abuse: A survey of 259 cocaine abusers. J. Clin., Psychiatry 48:47-50; 1987.

12. Jones, D. A.; Cheshire, N.; Moorhouse, H. Anorexia nervosa, bulimia and alcoholism-association of eating disorder and alcohol. J. Psychiatric Res. 19:377-380; 1985.

13. Kampov-Polevoy, A. B.; Kasheffskaya, O. P.; Sinclair, J. D. Initial acceptance of alcohol: gustatory factors and patterns of alcohol drinking. Alcohol 7:83-85; 1990.

14. Kiefer, S. W.; Bice, P. J.; Orr, M. R.; Dopp, J. M. Similarity of taste reactivity responses to alcohol and sucrose mixtures in rats. Alcohol 7:115-120; 1990.

15. Kiefer, S. W.; Lawrence, G. J. The sweet-bitter taste of alcohol: Aversion generalization to various sweet-quinine mixtures in the rat. Chem. Senses 13:633-641; 1988.

16. Krahn, D. D.; Gosnell, B. A. Fat-preferring rats consume more alcohol than carbohydrate-preferring rats. Alcohol 8:313-316; 1991.

17. Leon, G. R.; Carroll, K.; Chernyk, B.; Finn, S. Binge eating and associated habit patterns within college student and identified bulimic populations. Int. J. Eating Dis. 4:43-57; 1985.

18. Lester, D.; Greenberg, L. A. Nutrition and the etiology of alcoholism: The effect of sucrose, saccharin and fat on the self- selection of ethyl alcohol by rats. Q. J. Stud. Alcohol 13:553 $560 ; 1952$.

19. Li, T.-K.; Lumeng, L.; McBride, W. J.; Waller, M. B. Progress toward a voluntary oral consumption model of alcoholism. Drug Alcohol Depend. 4:45-60; 1979.

20. Marks-Kaufman, R.; Lipeles, B. J. Patterns of nutrient selection in rats orally self-administering morphine. Nutr. Behav. 1:33-46; 1982.

21. Mitchell, J. E.; Hatsukami, D.; Eckert, E. D.; Pyle, R. L. Characteristics of 275 patients with bulimia. Am. J. Psychiatry 142: 482-485; 1985.

22. Mook, D. G. Taste-evoked drinking in the rat: The influence of maintenance diet. Physiol. Behav. 26:595-599; 1981.

23. Morabia, A.; Fabre, J.; Chee, E.; Zeger, S.; Orsat, E.; Robert, A. Diet and opiate addiction: A quantitative assessment of the diet of non-institutionalized opiate addicts. Brit. J. Addiction 84: 173-180; 1989.

24. Nichols, J. R.; Hsiao, S. Addiction liability of albino rats: Breeding for quantitative differences in morphine drinking. Science $157: 561-563 ; 1967$.

25. Sinclair, J. D.; Kampov-Polevoy, A.; Stewart, R.; Li, T.-K. Taste preferences in rat lines selected for low and high alcohol consumption. Alcohol (in press)

26. Sinclair, J. D.; Le, A. D.; Kiianmaa, K. The AA and ANA rat lines, selected for differences in voluntary alcohol consumption. Experientia 45:798-805; 1989.

27. Stewart, R. B.; Grupp, L. A. A simplified procedure for producing ethanol self-selection in rats. Pharmacol. Biochem. Behav. 21:255-258; 1984 .

28. Weiss, G. Food fantasies of incarcerated drug users. Int, J. Addictions 17:905-912; 1982

29. Weiss, S.; Ebert, M. Psychological and behavioral characteristics of normal-weight bulimics and normal-weight controls. Psychosom. Med. 45:293-303; 1983.

30. Willenbring, M. L.; Morley, J. E.; Krahn, D. D.; Carlson, G. A.; Levine, A. S.; Shafer, R. B. Psychoneuroendocrine ef fects of methadone maintenance. Psychoneuroendocrinology 14:371-391; 1989.

31. Wise, R. A. The role of reward pathways in the development of drug dependence. Pharmacol. Ther. 35:227-263; 1987.

32. Yamamoto, M. E.; Block, G. D.; Ishii, E. Food patterns among adolescents: Influence of alcohol consumption. Alcoholism Clin. Exp. Res. 15:359; 1991 .

33. Young, P. T.; Greene, J. T. Quantity of food ingested as a measure of relative acceptability. J. Comp. Physiol. Psychol. 46:288294; 1953.

34. Yung, L.; Gordis, E.; Holt, J. Dietary choices and likelihood of abstinence among alcoholic patients in an outpatient clinic. Drug Alcohol Depend. 12:355-362; 1983. 